\title{
Perception of students on the teaching methodologies utilized at Khesar Gyalpo University of Medical Sciences of Bhutan
}

\author{
Karma Tenzin ${ }^{1}$, Deki Pem², Tempa Gyeltshen ${ }^{3}$ \\ ${ }^{I}$ Faculty of Postgraduate Medicine, KGUMSB, Thimphu, Bhutan \\ ${ }^{2}$ Faculty of Nursing and Public Health, KGUMSB, Thimphu, Bhutan \\ ${ }^{3}$ Faculty of Traditional Medicine, KGUMSB, Thimphu, Bhutan
}

\begin{abstract}
Introduction: Recently, there have been numerous innovations in the field of medical education. Teaching methodology is one of the areas that have received the most attention. The aim of this study was to assess the students' perceptions of the effectiveness of different teaching methods, teaching aids and forms of evaluation at two faculties under Khesar Gyalpo University of Medical Sciences of Bhutan. Methods: This analytical cross-sectional study was conducted between $1^{\text {st }}$ June and $31^{\text {st }}$ July 2015 using a self-administered questionnaire in 150 first year and 148 final year students from the Faculty of Nursing and Public Health and Faculty of Traditional Medicine. Each participant completed a questionnaire containing items soliciting their opinions on teaching methods, teaching tools, and assessment methods. Results: Modern teaching methods are being practiced at the two faculties studied under KGUMSB. PowerPoint presentation and overhead projector were most preferred by both the groups. Also there was lack of exposure to computer-assisted learning in both the groups. Conclusions: We conclude that the teaching methodologies at KGUMSB are in line with current trends. However, this study also reveals that there is a need to institute robust strategies to encourage more computer-assisted learning.
\end{abstract}

Keywords: Computer-assisted learning; Medical Education; Self-Administered Questionnaire.

\section{INTRODUCTION}

Recently, there have been numerous innovations in the field of medical education. Teaching methodology is one of the areas that have received the most attention. The primary aim was to improve the performance of the faculties, ultimately resulting in students becoming better and lifelong learners.

A learning process that encompasses all the three domains of learning, namely cognitive, affective and psychomotor domains is important for learning ${ }^{1}$. Recently, teaching techniques have evolved and numerous techniques have come into existence. With changing trends, most of the faculties are getting acquainted with web-based and problem-based learning ${ }^{1-3}$.

The Faculty of Nursing and Public Health (FNPH) and Faculty of Traditional Medicine (FoTM) are the pioneer institutes in medical education in Bhutan, with a proud history of nearly three decades behind them. It is appropriate at this point to conduct a study to objectively assess the perception of students regarding the various teaching methods, teaching aids and evaluation methods practiced at these two faculties. This study aims to demonstrate if the teaching methods practiced at these two faculties are in line with current trends.

Effective learning is not only achieved through good teaching methodologies and strategies ${ }^{4-5}$ but also by a learning environment that includes active interactions among faculty, group and student peers ${ }^{4}$. Until recently, medical education was based on traditional methods. However, it is changing due to availability of new technologies such as computer-assisted learning ${ }^{6}$ among others.

A Malaysian study reported ninety percent of students favored audio-visual aids with complementary use of chalk and blackboard ${ }^{3}$. A comparative study of different teaching and learning methods in India reported that most students preferred a combination of both old traditional methods and computerassisted learning. The study concluded that in order to gain knowledge it is better to opt for a combined teaching method ${ }^{6}$. In a study from India, $73 \%$ expressed satisfaction with normal lectures and $68 \%$ with discussion. Regarding teaching tools, $83 \%$ of the students agreed that the blackboard was the better mode of teaching. Regarding assessment, $85 \%$ of students preferred multiple choice questions compared to other modes of assessment ${ }^{5}$.

The above mentioned studies have focused on few areas of medical education. Therefore, this study was conducted to look at the teaching methodologies used by faculties under Khesar Gyalpo University of Medical Sciences of Bhutan (KGUMSB).

\section{METHODS}

This analytical cross-sectional study was conducted amongst the students from FNPH and the FoTM under KGUMSB in June and 
July 2015. Prior to the commencement of data collection, the proposal was submitted to Research Ethics Board of Health for ethical clearance (Ref.No.REBH/PO/2014/015 dated 12 ${ }^{\text {th }}$ May 2015). Clearance from both teaching faculties was also obtained.

For this purpose, input from the students was collected from all 150 students (both males and females) in first year students (Group 1) and all 148 students (both males and females) in the final year students (Group 2) of 2014-2015. Data were collected using a specially designed questionnaire comprising of points relating to teaching methodology and assessment techniques in KGUMSB, Thimphu.

All participants were explained the purpose of the study and participation was voluntary. Written informed consent was obtained. Participants were required to specify the degree to which they agree with each statement on a Likert scale ranging from 1 to $5(1=$ strongly disagree to $5=$ strongly agree $)$. All personal identifiable information was protected through use of a coding system. The completed response sheets were collected and entered in Microsoft Excel and calculated in frequencies and proportions collapsed into "agree", "neutral", and "disagree".

\section{RESULTS}

Overall, both groups had exposure to various teaching methods. However, of the 150 first year students, only $60 \%(90 / 150)$ had a favourable impression of role play compared to $68.24 \%(101 / 148)$ of final year students. Similarly among first year students, $55.33 \%(83 / 150)$ had a favourable impression of brainstorming sessions as being a useful teaching method, compared to $82.43 \%$ $(122 / 148)$ of final year students. While 26.07\% (40/150) of first year students were undecided regarding the effectiveness of brainstorming sessions, $27.70 \%$ (41/148) of final year students were undecided about the effectiveness of role play as a teaching method.

Students' perceptions on teaching tools revealed that only $53.33 \%(80 / 150)$ of first year students felt the blackboard was an effective teaching tool. On the contrary, $73.64 \%(109 / 148)$ of them thought an overhead project was effective and $83.78 \%$ (124/148) thought PowerPoint presentations were anequally effective teaching tool. However, other teaching tools like use of YouTube and animations and web-based learning were not popular among either group.

Over the course of training at KGUMSB, students' perceptions as to the effectiveness of the old-school blackboard decreases from $53 \%$ to $39 \%$, while the perception of the effectiveness of technology-based teaching improves $(61 \%$ to $74 \%$ in OHP, 75 to $84 \%$ in PP, $39 \%$ to $45 \%$ with Youtube, and $41 \%$ to $44 \%$ with internet).

Both student groups thought that most of the methods of assessment listed were equally important. More than $90 \%$ from each group thought multiple choice questions, fill in the blanks, matching type, and short answer questions were equally effective.

Only $56.67 \%, 52.67 \%$ and $65.33 \%$ of first year students thought VIVA VOCE, OSPE/OSCE and bedside examination respectively were effective methods of assessment. In contrast, for the same, $83.78 \%, 80.29 \%$ and $80.41 \%$ of final year students thought these were effective. The students' perceptions of VIVA VOCE as well as all the practical evaluation methods increase dramatically over the course of training.

In addition, both the student groups rated essay type questions low in comparison to the other methods of assessment.

\section{DISCUSSION}

The study overall revealed that the level of perception of the various teaching methodologies between first and final year students was almost similar. In addition, the study also revealed that the topics covered during the lectures were interesting with $74.60 \%$ of first year and $85.80 \%$ of final year students either agreeing or strongly agreeing, in contrast to some of the studies in the region 6 . Only $55.33 \%$ of first year students agreed or strongly agreed that brainstorming session were effective, though $82.43 \%$ of final year students thought it was a useful teaching method. This is in contrast to findings reported in other studies which reported brainstorming session as more effective in gaining knowledge.

Only $53.33 \%$ of first year and $38.51 \%$ of final year students thought black/white board was an effective tool ${ }^{7}$. On the other hand, OHP and PowerPoint presentation were both ranked highly as effective teaching tools. These findings contrast with the ones reported to other studies 6 . Other teaching tools like YouTube, animations and web-based learning were not popular among the groups of both first and final year. This is a trend which is also reported by other studies ${ }^{8}$. This could be attributed to either poor computer literacy among the students, or poor computer literacy/ confidence amongst the teaching faculty.

Both student groups thought that most of the methods of assessment listed were important. The typical ways of assessment which students are familiar with from secondary education were looked at favourably by both groups.

The students' perceptions of VIVA VOCE and clinical examination methods dramatically improved during their years of training. This is similar to the findings reported by the studies outside $^{8}$. This is most probably due to increasing awareness regarding the importance of these assessment methods as students graduate to higher levels.

In addition, both the groups rated essay type questions low in comparison to the other methods of assessment, a trend that is similar to other institutes in the region. However, approximately $25 \%$ more of the final year students had positive perceptions to essay type questions than the first year students. This could be attributed to the older students seeing the benefit of being able to explain complex and interconnected health processes, something that comes with increasing medical knowledge. 


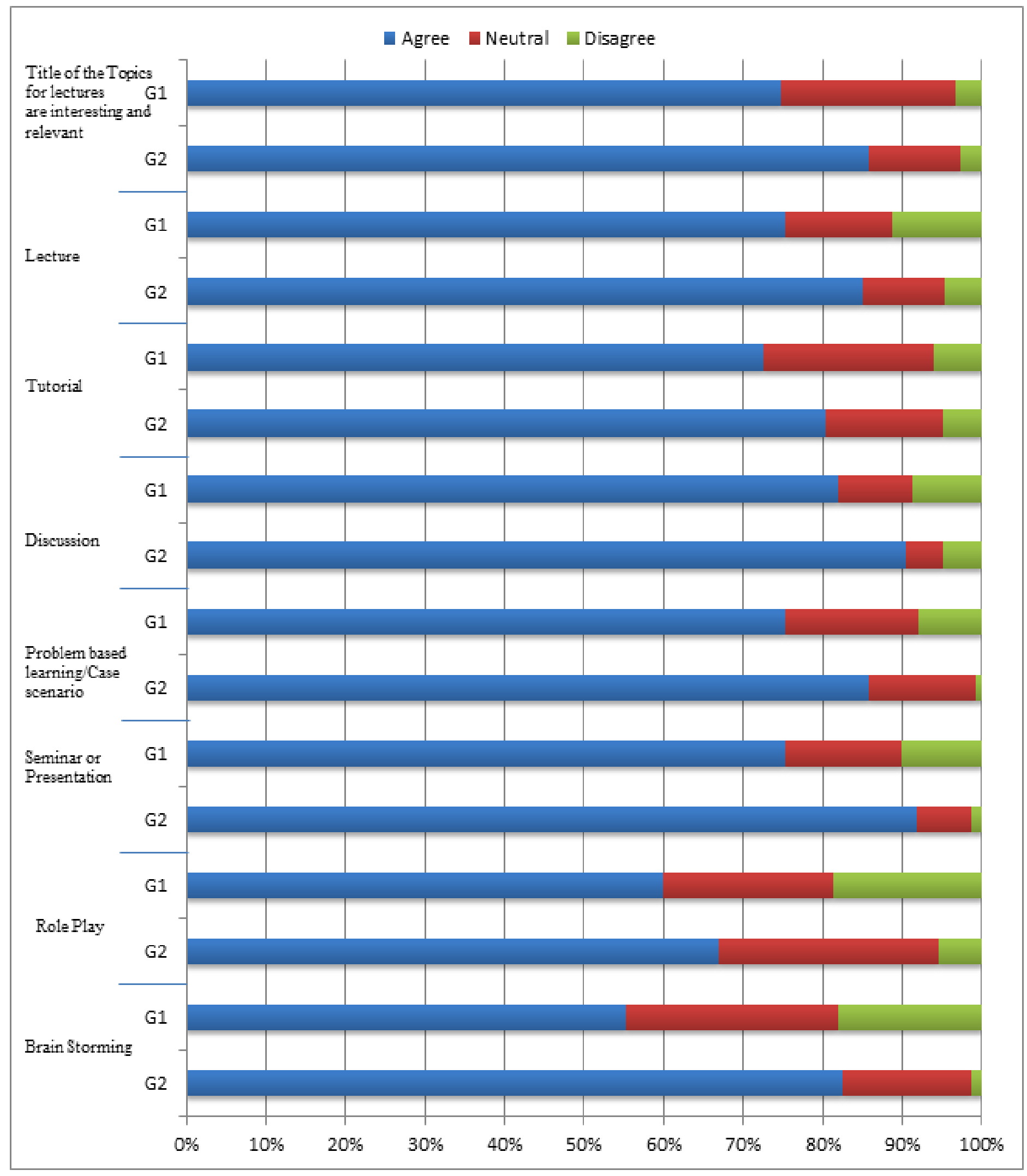

Figure 1. Rating of various teaching methods practiced 


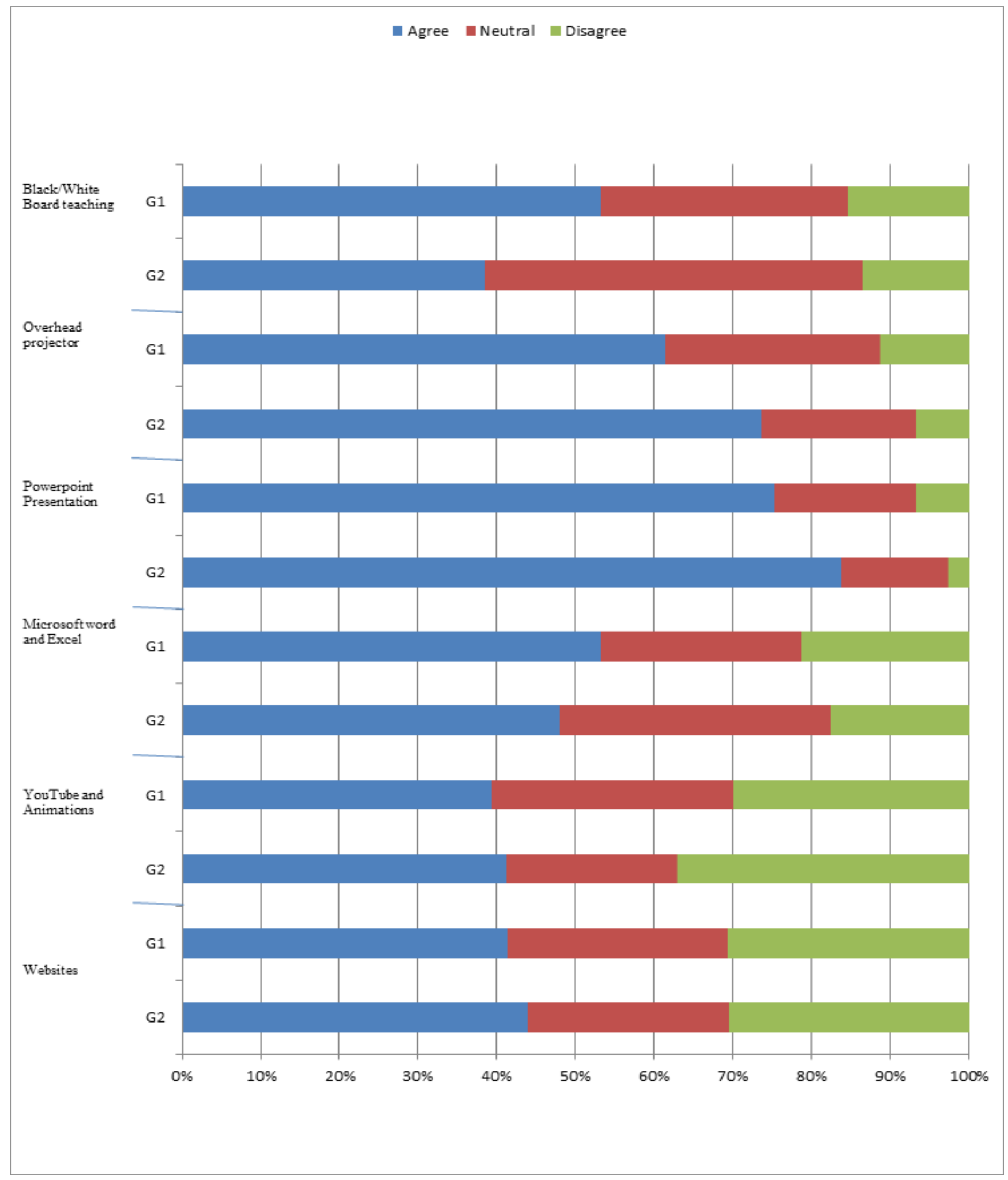

Figure 2. Rating on effectiveness of various teaching tools 


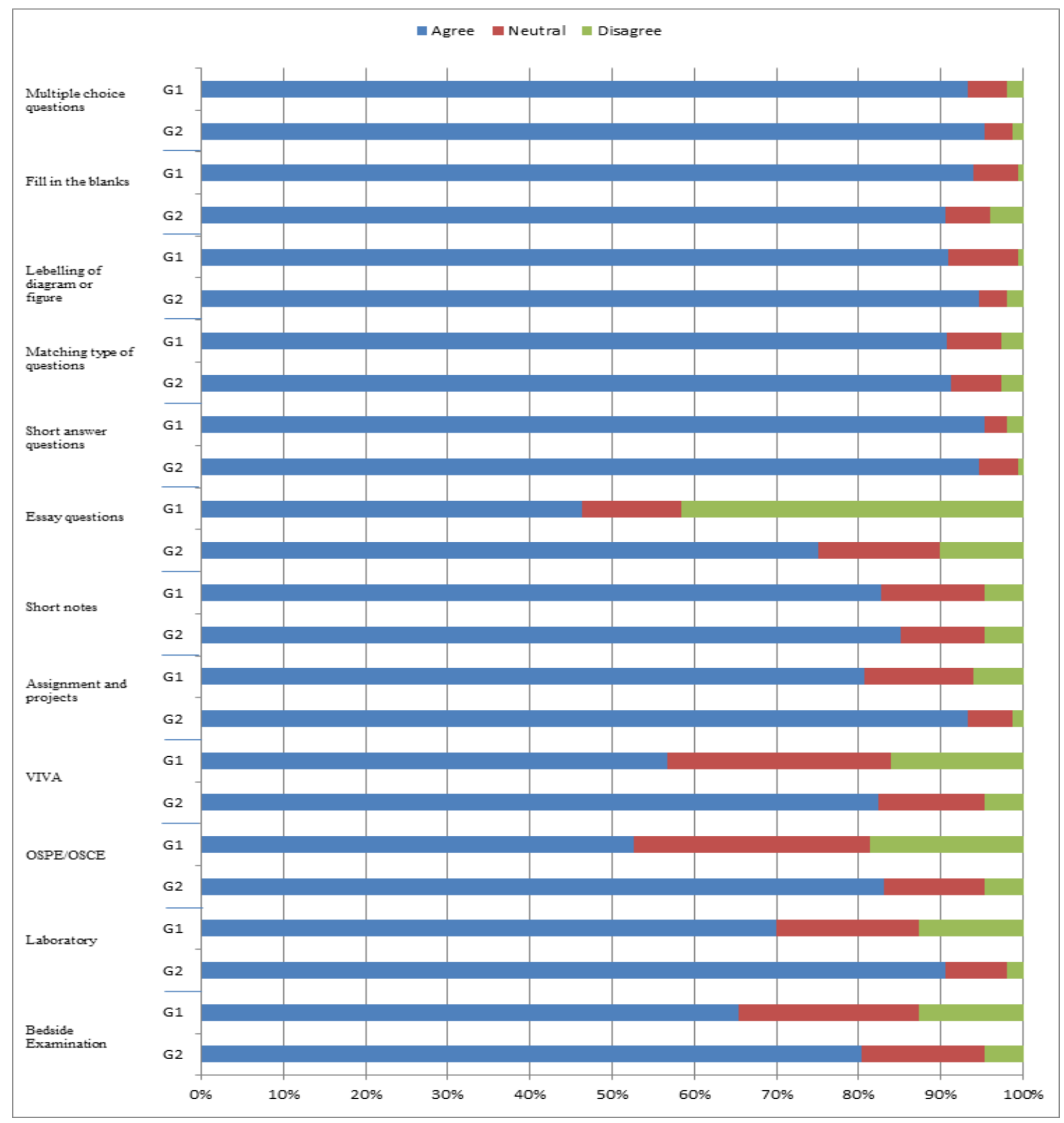

Figure 3. Rating on most effective methods of evaluation/assessment 


\section{CONCLUSIONS}

The study concluded that there was improvement in level of perception on the teaching methodologies as students graduated from first year to the final year. However, it was also observed that both groups were of the view that the use of black/white board and IT-based learning were not effective. Limitations of this study were that the authors choose to use only numbers and proportions, making the study statically weak. Therefore in the future studies can be conducted in specific section with more statistical tests. Also each group was not divided into female and male and there may be gender differences in opinions of teaching methods. The recommendation from the current study is that while the university must be commended for having all the teaching tools and techniques which students perceive are effective in their teaching and learning process, there is, however a need to put in place a robust strategy to encourage more ITbased learning (Computer-assisted learning).

\section{ACKNOWLEDGEMENTS}

The authors would like to thank the Deans of the Faculty of Nursing and Public Health and the Faculty of Traditional Medicine and all the participants. Special gratitude also goes to Dr. Ripa Chakma and the office of the President, KGUMSB for logistical support.

\section{REFERENCES}

1. Kumar MP. Preferences of undergraduate medical studentsElectronic and non-electronic teaching methods in pathology. Int J of Res in Health Sci. 2013;1(3):239-41. [Full Text]
2. Muneshwar JN, Mirza SB, Zingade US, Khan ST. A questionnaire based evaluation of teaching methods amongst MBBS group. Int J Med Res Health Sci.2013;2(1):19-22. [Full Text]

3. Ismail S, Nor Iza AR, Nasir M, Norhasiza MJ, Aminatul IBH, Liyana ABA, et al. Preference of teaching and learning methods in a new medical school of Malaysia Journal of Applied Pharmaceutical Science. 2014; 02:48-55. [Full Text | DOI]

4. Mostafa A, Usama AS, Tarek S. Medical students'perceptions of teaching evaluation in psychiatry. Basic Research Journal of Education Research and Review. Nov 2012;1(5):81-4. [Full Text]

5. Dash SK, Patro S, Behera BK. Teaching Methods and Its Efficacy an Evaluation by the Group. J Indian Acad Forensic Med. Oct-Dec 2013;35(4). 321-4. [Full Text | DOI]

6. Kharkar AR, Salve SB, Dase RK, Lande HB. A comparative study of different teaching, learning methods amongst the MBBS students. Int J current Med. and AplSci 2013;1(3). 05-8.

7. Baruah M, Patel L. Evaluation of different teaching methods used in physiology lectures. Indian Journal of Basic and Applied Medical Research. Dec 2014;4(1):271-6. [Full Text | DOI]

8. Garg A, Rataboli PV, Muchandi K. Students' opinion on the prevailing teaching methods in pharmacology and changes recommended. Indian J Pharmacol. June 2004; 36(3):155-8. [Full Text]

\section{AUTHORS CONTRIBUTION}

Following authors have made substantial contributions to the manuscript as under:

KT: Concept, design, literature search, data collection and analysis, manuscript writing and review.

DP: Concept, data collection and analysis, manuscript review.

TG: Concept, data collection and analysis, manuscript review.

Author agree to be accountable for all respects of the work in ensuring that questions related to the accuracy and integrity of any part of the work are appropriately investigated and resolved.

CONFLICT OF INTEREST

None

GRANT SUPPORT AND FINANCIAL DISCLOSURE

None 